\title{
Posterior tibial nerve stimulation for the treatment of faecal incontinence following obstetric anal sphincter injury
}

Running title: PTNS in post-obstetric faecal incontinence

Santosh Sanagapalli1 ${ }^{1,2,3}$, Suzanne Harrington ${ }^{4}$, Natalia Zarate-Lopez ${ }^{1}$, Anton Emmanuel $^{1}$

${ }^{1}$ GI Physiology Unit, University College London Hospital, United Kingdom

${ }^{2}$ St Vincent's Hospital Sydney, Australia

3 University of New South Wales, Sydney, Australia

${ }^{4}$ Royal College of Surgeons of Ireland, Dublin

\section{Institutional details}

GI Physiology Unit, Elizabeth Garrett Anderson Wing, University College Hospital, 235 Euston Rd, London, United Kingdom, NW1 2BU

\section{Correspondence}

Dr S. Sanagapalli 
e: Santosh.Sanagapalli@svha.org.au

a: Department of Gastroenterology, St Vincent's Hospital Sydney, Darlinghurst NSW 2010, Australia

t: +6183821111

\section{Disclosures of Interest}

A Emmanuel is supported by the Biomedical Research Centre at University College London. There is no other financial support or conflict of interest to declare for any other author. 


\section{$\underline{\text { Abstract }}$}

\section{Objectives}

Obstetric anal sphincter injuries (OASI) are a major risk factor for faecal incontinence. Neuromodulation is often used as second-line therapy for faecal incontinence, but evidence for its efficacy is conflicting. We aimed to evaluate the efficacy and predictive factors of posterior tibial nerve stimulation for obstetric anal sphincter injury-induced faecal incontinence.

\section{Materials and Methods}

Consecutive females with faecal incontinence related to past OASI who had not responded to first line therapy and had received 8-12 weeks of posterior tibial nerve stimulation were included. Subjects aged over 50 and/or having other causes of faecal incontinence were excluded. Patients underwent anorectal physiology and endoanal ultrasound pre-therapy. Symptom burden was evaluated pre- and post-therapy using Rockwood and Wexner scales. A Wexner score reduced to below 10 or halved was used to define responders.

\section{Results}

37 females (mean age 38 years, median parity 2) were included. 17 (46\%) had ultrasonographically-visualised anal sphincter defects and $41 \%$ had a history of third or second-degree perineal tears. 14 subjects (38\%) were deemed responders. Compared to non-responders, responders had lower baseline rectal distension thresholds and tended 
to have disrupted (59\%) than intact sphincters $(20 \%, P<0.01)$. Responders demonstrated improvement in Rockwood score for depression and embarrassment, visual analogue score for bowel symptoms and stool consistency (median baseline Bristol score 5, to 3 post-therapy; $P<0.01)$.

\section{Conclusions}

Of a well-defined cohort of females with faecal incontinence secondary to OASI, $38 \%$ responded to posterior tibial nerve stimulation. Much of this improvement may relate to improvement in stool consistency.

\section{Keywords}

Faecal incontinence; posterior tibial nerve stimulation; obstetric anal sphincter injury; neuromodulation; obstetric tear

\section{Abbreviations}

FI, faecal incontinence; IQR, interquartile range; OASI, obstetric anal sphincter injury; PTNS, posterior tibial nerve stimulation; SNS, sacral nerve stimulation; VAS, visual analogue scale 


\section{Introduction}

Obstetric anal sphincter injury (OASI) is defined as a perineal tear occurring during vaginal delivery, associated with partial or complete rupture of external and/or internal anal sphincters; the reported incidence is up to $11 \%$ of vaginal births.(1) OASI is a major predisposing factor for, and associated with a significant incidence of, faecal incontinence (FI) in adult women.(2-4) Although a nonfatal condition, FI has a major impact on quality of life with significant pyschosocial effects amongst sufferers.

Management of FI begins with conservative measures including dietary advice, stool bulking fiber supplements, constipating drugs and biofeedback therapy. $(5,6)$ Neuromodulation is now widely used as a second-line treatment when conservative options fail. Sacral nerve stimulation (SNS) was the first form of neuromodulation to be widely used for FI.(7) Posterior tibial nerve stimulation (PTNS) was subsequently introduced to neuromodulate the sacral nerve plexus remotely, in an attempt to produce the same effects in a simpler, cheaper, safer and less invasive fashion. The mechanism of action of both SNS and PTNS is, however, unknown; no changes in anorectal physiology are found following neuromodulation, even when there is symptomatic benefit. It is proposed that modulation of central pathways controlling colorectal motility and afferent sensory perception may contribute. $(5,8)$

Evidence regarding the efficacy of PTNS for FI is conflicting. Whereas a number of observational studies and a small randomized trial involving a sham arm all demonstrated benefits for PTNS, $(9,10)$ a recently published large randomized trial found 
no significant benefit of PTNS over sham stimulation.(11) While differences in methodology and failure to account for placebo effect undoubtedly explain some of the discrepancy, patient selection may also be one potential cause of these conflicting results. Therefore, the aim of the present study is to, through use of a responder analysis, identify factors associated with and potentially predictive of treatment response among a specific cohort of females who underwent PTNS for FI related to OASI.

\section{Material and Methods}

\section{Study Design}

A retrospective analysis of prospectively collected data was performed. Consecutive females who received PTNS treatment for FI associated with past OASI were included. FI was defined as the accidental or involuntary loss of liquid or solid faeces. These subjects were recruited from a single tertiary referral centre between 2012 and 2015. They had all failed conservative therapies comprising antidiarrheal drugs, stool bulking agents, and biofeedback as per our Unit protocol.(12,13) Exclusion criteria included the presence of any other potential cause of FI, whether or not it was the primary aetiology or occuring in combination with OASI. Such causes comprised especially patients with neurological conditions (spinal cord injury, multiple sclerosis, Parkinson's disease and diabetic neuropathy) as well as those with anorectal anatomic abnormalities or previous anal surgery. Females over 50 years were also excluded given the increased likelihood of other such contributing factors being present. These measures together excluded three subjects, but ensured that the etiology of FI in the included patients was purely obstetric. We also excluded two patients who failed to attend their prescribed PTNS sessions in a 
regular fashion. This left us with a study population of 37 subjects, all of whom had undergone anorectal physiology testing and endoanal ultrasound prior to PTNS therapy.

Ethics committee approval was not necessary as this was a retrospective analysis of standard practice in the unit.

\section{PTNS}

Patients received PTNS according to a standardized nurse-administered protocol in a similar fashion as has been previously described.(10,14) A 34 gauge needle was inserted $5 \mathrm{~cm}$ cephalad to medial malleolus and $2 \mathrm{~cm}$ posterior to tibia at a $60^{\circ}$ angle with a base electrode placed on the ipsilateral leg. Therapy was performed with the patient in sitting or supine position. Both electrodes are then connected to the neurostimulator device (Urgent PC, Cogentix, Manchester, UK). Correct needle placement confirmed by motor and/or sensory response (flexion of big toe, fanning of all toes or tingling sensation of foot extending to all toes). A suitable neurostimulation setting was then chosen whereby the patient was able to comfortably receive 30 minutes of therapy; subjects received neuromodulation therapy at this optimal setting on a weekly basis for a minimum of 8 weeks. If no response was obtained at 8 weeks then therapy was ceased, given little likelihood of subsequent treatment response; however those who exhibited some response during the first 8 weeks continued therapy so that they completed 12 weeks in total.(15) 


\section{Outcomes}

Characteristics of study patients at baseline including age, number of vaginal deliveries and obstetric risk factors for FI were collected. Validated measures of symptom severity in patients with FI were administered both at baseline and immediately following therapy:

- The Wexner Incontinence questionnaire is a validated and reproducible measure for assessing severity of fecal incontinence; it does so on a scale of 0 to 20 , with 0 representing the absence of any symptoms and 20 corresponding to the greatest severity of symptoms.(16)

- The Rockwood score is a validated quality of life measure specific to fecal incontinence.(17) It assigns a score for each of 4 domains, lifestyle, coping/behaviour, depression/self perception and embarrassment. These were scored between 1 and 5, with 1 indicating a lower functional status or quality of life.

- Visual analogue scales (VAS) were used to assess bowel and bladder symptoms. Each VAS was anchored between 0 and 100, with $0=$ no problems with function and $100=$ worst possible problems with function, a separate scale being used for bowel and bladder function.

- The Bristol Stool Form Scale has not been validated for use specifically in FI, but is a valid and reliable 7-point scale used extensively in clinical and research settings for measurement of stool form in both healthy patients and those with diarrhea.(18) Type 1 stools are excessively hard and dry whereas Type 7 are the most watery and Type 3 and 4 are normal stools. 
All patients were considered as one cohort. Subjects were classified as responders to the treatment adminstered if they fulfilled the dual criteria of: reduction in Wexner score to below 10, and halving of the baseline score, as has been used on previous occassions.(1921) Subjects not fulfilling either criteria were deemed non-responders. Characteristics of responders and non-responders were then compared in order to identify factors potentially predictive of response to therapy.

\section{Statistical Analysis}

Data analysis was performed using STATA software. Normally distributed data were expressed as mean and standard deviation, and median and interquartile range (IQR) were measured for nonparametric data. Paired t-tests compared normally distributed data at baseline and conclusion of treatment to determine how PTNS impacted Wexner score, and Mann-Whitney U tests compared nonparametric data. Chi squared test was used to compare quantitative data. A $P$-value of $<0.05$ was considered statistically significant.

\section{$\underline{\text { Results }}$}

\section{Demographics}

Thirty-seven female patients fulfilled the criteria and were included in the analysis. Mean age at treatment was 38 (range 24-48) and was similar in responders and nonresponders $(P=0.66)$. Median parity was $2($ IQR $1-2)$. Mean time since injury was 5.2 years (range $0.5-9.0)$. Perineal tear type was $4^{\text {th }}$ degree in 5 patients $(14 \%)$, $3^{\text {rd }}$ degree in 15 
(41\%), $2^{\text {nd }}$ degree in $15(41 \%)$ and $1^{\text {st }}$ degree in $2(5 \%)$. Thirty-two patients $(86 \%)$ had repair of the perineal tear post-delivery and most of these were primary repairs only (28 primary repair only, 4 secondary repair). 22 patients (69\%) had a history of instrumentation during vaginal delivery (17 forceps, 3 Ventouse extraction, 2 both). Twenty-three patients (62\%) had a history of episiotomy and ten subjects (27\%) had a history of delivering a baby with a birthweight $>4 \mathrm{~kg}$. Seventeen subjects $(46 \%)$ had ultrasonographically assessed defects of the external anal sphincter with or without an additional internal anal sphincter defect

Of the total cohort, 14 patients (38\%) patients demonstrated a response to treatment assessed by the Wexner score as described above. Mean Wexner score at baseline was 13 in both responders and non-responders, however this dropped to 4 in responders post therapy $(P<0.01$ c.f. baseline) whereas there was no significant change in Wexner post therapy in the non-responders. All patients continued on to the maintenance phase of PTNS therapy.

\section{Obstetric risk factors for FI and treatment response}

Overall, no association was found between the presence or absence of obstetric risk factors for FI and response to PTNS (Table 1). The likelihood of treatment response did not differ between women who had delivered high birthweight babies, defined as $>4 \mathrm{~kg}$, and those who had not $(P=0.87)$. Similarly, a history of episiotomy $(P=0.84)$ or of instrumentation during vaginal delivery $(P=0.64)$ had no bearing on treatment response., The majority of patients (86\%) had undergone perineal repair. Those who had secondary 
repair of obstetric perineal tears had a universally poor treatment response to PTNS $0 \%$ responders) but the numbers were small and overall, there was no significant difference found in likelihood of treatment success between those who had primary, secondary versus no history of repair of an obstetric tear $(P=0.27)$. There was no correlation between the severity of obstetric perineal tear and the likelihood of response $(P=0.72)$, though there was a trend towards worse likelihood of response with greater severity of tear (Table 1).

\section{Association between physiological parameters and treatment response}

Comparing physiological parameters at baseline between responders and nonresponders, the only differentiating feature was in rectal sensitivity to balloon distension, with significantly lower mean threshold volume (26 $\pm 9 \mathrm{~mL}$ vs $35 \pm 13 \mathrm{~mL}, P=0.02)$ and urge volumes ( $56 \pm 16 \mathrm{~mL}$ vs $72 \pm 26 \mathrm{~mL}, P=0.03$ ) prior to treatment amongst responders compared with non-responders. In contrast, resting, squeeze and cough pressures, as well as sensitivity of both anus and rectum to electrical stimulation, were similar at baseline between responders and non-responders (Table 2).

\section{Association between sphincter integrity and treatment response}

Of responders, the majority had ultrasonographically visible defects in integrity of the internal sphincter, external sphincter or both; in contrast, non-responders tended to have intact sphincters as visualised by endoanal ultrasound. In fact, $59 \%$ of those with defective sphincters responded to PTNS compared to only $20 \%$ of those with intact sphincters $(P<0.01)$. 


\section{Association between improvement in Wexner score and other outcome measures}

At baseline, responders were in fact more impaired, as assessed by the VAS for bowel symptoms, compared to non-responders (mean VAS bowel score $63 \pm 19$ vs $49 \pm 20$, $P=0.03$ ); however in terms of the other outcome measures of symptom severity assessed, there were no statistically significant differences.

Following treatment, the greater improvement in Wexner score in responders was associated with corresponding greater improvements in some (but not all) of the other measures of symptom severity when compared with the non-responders (Table 3). Significant improvement was noted in the Rockwood score for depression and embarrassment, as well as the mean VAS score for bowel symptoms in responders. No improvement in any of these outcome measures was found among non-responders.

Responders also exhibited a significant improvement in stool consistency; the median Bristol Stool Form score improved from $5(\mathrm{IQR}=1)$ to $3(\mathrm{IQR}=2)$ with treatment in responders $(P<0.01)$ while no significant improvement in stool consistency was noted in non-responders.

\section{$\underline{\text { Discussion }}$}


We report on the utility of PTNS in patients with faecal incontinence caused singularly by obstetric injury, identifying a $38 \%$ response rate with such neuromodulation. This is the first series to report on this well-defined patient group. Our response rate is lower than that seen in most other case series of PTNS in 'all-comers' with FI, where response rates of $63-82 \%$ were reported.(9) The differences might be due to the careful selection of this patient group, or alternatively due to the methodology used to assess clinical response. Of note, one series with a similar outcome measure as the present study also reported a $38 \%$ response rate.(22) A recent study evaluated the efficacy of three weeks of PTNS in patients with OASI-related FI, and found that the response rate was far superior among older, postmenopausal patients who were excluded from the present study.(23) We chose to exclude such patients from our study as it is more likely that these patients have other secondary non-obstetric factors contributing to FI, which can be difficult to identify and could therefore compromise the validity of our findings. Another randomized controlled trial of transcutaneous PTNS vs. sham found significant improvement in the Wexner score in the treatment group despite not improving the number of incontinence episodes,(24) highlighting the impact that choice of outcome measure can make.(25) We chose reduction in Wexner score rather than a percentage reduction in FI episodes as our primary outcome since it is more holistic, multifaceted and relevant to the patient.(26)

The response to therapy demonstrated did not require sphincter integrity, in fact patients with a disrupted sphincter seemed to do better. This is not necessarily surprising, given that modern hypotheses regarding the mechanism of PTNS emphasise the role of activation of multiple somato-visceral reflexes rather than simple enhancement of anal sphincter activity.(27) However, it is of importance as, to date, the majority of studies 
exploring the efficacy of PTNS in FI have not reported on sphincter integrity as a predictive factor and often excluded patients with sphincter defects.(22, 28, 29) This finding adds further weight to the argument that patients with sphincter defects should not be precluded from trialling PTNS.

Analysing the physiological parameters at baseline, there was no factor associated with treatment success other than that responders tended to have slightly greater sensitivity to mechanical stimulus, as measured by a statistically significant lower urge and maximal tolerated volume in this group. Given that rectal hypersensitivity is an important parameter contributing to faecal incontinence,(30) this finding is noteworthy. It may be that modification of rectal sensitivity is an important mechanism by which neuromodulation improves symptoms, as demonstrated previously by Fassov et al.(31) However as the magnitude of difference found in the present study was small, definitive conclusions cannot be drawn; but it merits re-examination in a future larger study, ideally with remeasurement of rectal sensitivity post-therapy also.

Whilst we did not find any statistically significant correlation between any obstetric risk factors and response to PTNS, there was a trend to better response among those who had lesser severity of perineal trauma (50\% responders for Grade I tears, $20 \%$ responders for Grade IV tears), and in those who had no history of perineal repair versus those who did, with all secondary repairs being treatment failures (Table 1). Our study may have been underpowered to detect significant differences between these subgroups, but on the other hand, if this was a true association, it would seem to be incongruous with our other 
finding that those with disrupted sphincters responded better to PTNS. To our knowledge only one other study has examined for the presence of such an association and if anything, found that Grade IV tears tended to do better, in contrast to our findings; though again the differences were not statistically significant.(23) Ultimately, a higher powered study is needed before drawing definitive conclusions.

Among those classed as responders, there was a significant improvement in the depression and embarrassment domains of the quality of life score; this is in keeping with the previously demonstarted correlation between Wexner score and quality of life.(32) However, we did not observe corresponding improvements in other quality of life domains of lifestyle and coping. Looking closer at the questionnaire, the reason for this discrepancy is likely due to the quality of life aspects covered in the latter two domains being more multifactorial and less specific to incontinence, for example, questions asking about level of sexual desire.(25) Improvement in the VAS for bowel symptoms, another patient-centric outcome measure, was also observed; this is in keeping with the idea that those that we classified as having demonstrated benefit from PTNS indeed derived a meaningful improvement in symptoms and quality of life from the therapy.

The obvious limitation of this study is the absence of a control group. While we acknowledge the potential for high placebo responses in trials of FI therapies, this study still adds valuable information by circumventing some of the problems with the randomized controlled trials that have been published to date; namely, by assessing 
efficacy using a more patient-centric outcome measure (Wexner score), and by presenting data on a targeted patient group.

\section{Conclusion}

In this carefully worked-up cohort of patients with FI purely due to past OASI, we found a 38\% response rate following PTNS therapy, as assessed by improvement in Wexner score. Along with improvement in the Wexner score, responders to therapy also demonstrated significant improvements in other global measures of wellbeing including depression and embarrassment quality of life scores, as well as in the VAS for bowel symptoms. The presence of ultrasonographically identified defects in the external and/or internal anal sphincter predicted treatment success.

\section{$\underline{\text { References }}$}

1. Dudding TC, Vaizey CJ, Kamm MA. Obstetric anal sphincter injury: incidence, risk factors, and management. Annals of surgery. 2008;247(2):224-37.

2. Rao SSC. Diagnosis and Management of Fecal Incontinence. The American Journal of Gastroenterology. 2004;99(8):1585-604.

3. Hayden DM, Weiss EG. Fecal incontinence: etiology, evaluation, and treatment. Clinics in colon and rectal surgery. 2011;24(1):64-70.

4. Marsh F, Lynne R, Christine L, Alison W. Obstetric anal sphincter injury in the UK and its effect on bowel, bladder and sexual function. European journal of obstetrics, gynecology, and reproductive biology. 2011;154(2):223-7. 
5. Duelund-Jakobsen J, Worsoe J, Lundby L, Christensen P, Krogh K. Management of patients with faecal incontinence. Therapeutic advances in gastroenterology. 2016;9(1):86-97.

6. Norton C, Cody JD. Biofeedback and/or sphincter exercises for the treatment of faecal incontinence in adults. The Cochrane database of systematic reviews. 2012;7.

7. Tan E, Ngo N-TT, Darzi A, Shenouda M, Tekkis PP. Meta-analysis: sacral nerve stimulation versus conservative therapy in the treatment of faecal incontinence. International journal of colorectal disease. 2011;26(3):275-94.

8. Thomas GP, Dudding TC, Rahbour G, Nicholls RJ, Vaizey CJ. A review of posterior tibial nerve stimulation for faecal incontinence. Colorectal disease : the official journal of the Association of Coloproctology of Great Britain and Ireland. 2013;15(5):519-26.

9. Horrocks EJ, Thin N, Thaha MA, Taylor SJC, Norton C, Knowles CH. Systematic review of tibial nerve stimulation to treat faecal incontinence. British Journal of Surgery. 2014;101(5):457-68.

10. George AT, Kalmar K, Sala S, Kopanakis K, Panarese A, Dudding TC, et al. Randomized controlled trial of percutaneous versus transcutaneous posterior tibial nerve stimulation in faecal incontinence. The British journal of surgery. 2013;100(3):330-8.

11. Knowles CH, Horrocks EJ, Bremner SA, Stevens N, Norton C, O'Connell RP, et al. Percutaneous tibial nerve stimulation versus sham electrical stimulation for the treatment of faecal incontinence in adults (CONFIDeNT): a double-blind, multicentre, pragmatic, parallel-group, randomised controlled trial. Lancet (London, England). 2015;386(10004):1640-8. 
12. Preziosi G, Raptis DA, Storrie J, Raeburn A, Fowler CJ, Emmanuel A. Bowel biofeedback treatment in patients with multiple sclerosis and bowel symptoms. Diseases of the colon and rectum. 2011;54(9):1114-21.

13. Norton C, Chelvanayagam S, Wilson-Barnett J, Redfern S, Kamm MA. Randomized controlled trial of biofeedback for fecal incontinence. Gastroenterology. 2003;125(5):1320-9.

14. Hotouras A, Murphy J, Allison M, Curry A, Williams NS, Knowles CH, et al. Prospective clinical audit of two neuromodulatory treatments for fecal incontinence: sacral nerve stimulation (SNS) and percutaneous tibial nerve stimulation (PTNS). Surgery Today. 2014;44(11):2124-30.

15. NICE. Percutaneous tibial nerve stimulation for faecal incontinence London2011. Available from: nice.org.uk/guidance/ipg395.

16. Vaizey CJ, Carapeti E, Cahill JA, Kamm MA. Prospective comparison of faecal incontinence grading systems. Gut. 1999;44(1):77-80.

17. Rockwood TH, Church JM, Fleshman JW, Kane RL, Mavrantonis C, Thorson AG, et al. Fecal incontinence quality of life scale: Quality of life instrument for patients with fecal incontinence. Diseases of the Colon \& Rectum. 2000;43(1):9.

18. Blake MR, Raker JM, Whelan K. Validity and reliability of the Bristol Stool Form Scale in healthy adults and patients with diarrhoea-predominant irritable bowel syndrome. Alimentary pharmacology \& therapeutics. 2016;44(7):693-703.

19. Takahashi-Monroy T, Morales M, Garcia-Osogobio S, Valdovinos MA, Belmonte C, Barreto C, et al. SECCA(R) Procedure for the Treatment of Fecal Incontinence: Results of Five-Year Follow-Up. Diseases of the Colon \& Rectum. 2008;51(3):355. 
20. Sanchez JE, Brenner DM, Franklin H, Yu J, Barrett AC, Paterson C. Validity of the $\geq 50 \%$ Response Threshold in Treatment With NASHA/Dx Injection Therapy for Fecal Incontinence. Clinical and translational gastroenterology. 2015;6.

21. Mellgren A, Matzel KE, Pollack J, Hull T, Bernstein M, Graf W, et al. Long-term efficacy of NASHA Dx injection therapy for treatment of fecal incontinence. Neurogastroenterology and motility : the official journal of the European Gastrointestinal Motility Society. 2014;26(8):1087-94.

22. de la Portilla F, Rada R, Vega J, González CA, Cisneros N, Maldonado VH. Evaluation of the use of posterior tibial nerve stimulation for the treatment of fecal incontinence: preliminary results of a prospective study. Diseases of the colon and rectum. 2009;52(8):1427-33.

23. Rydningen MB, Dehli T, Wilsgaard T, Lindsetmo RO, Kumle M, Stedenfeldt M, et al. Sacral neuromodulation for faecal incontinence following obstetric sphincter injury outcome of percutaneous nerve evaluation. Colorectal disease : the official journal of the Association of Coloproctology of Great Britain and Ireland. 2016.

24. Leroi AM, Siproudhis L, Etienney I, Damon H, Zerbib F, Amarenco G, et al. Transcutaneous Electrical Tibial Nerve Stimulation in the Treatment of Fecal Incontinence: A Randomized Trial (Consort 1a). The American Journal of Gastroenterology. 2012;107(12):1888-96.

25. Vaizey CJ. Faecal incontinence: standardizing outcome measures. Colorectal Disease. 2014;16(3):156-8.

26. Wald A. New Treatments for Fecal Incontinence: Update for the Gastroenterologist. Clinical Gastroenterology and Hepatology. 2014;12(11):1783-8.

27. Gourcerol G, Vitton V, Leroi AM, Michot F, Abysique A, Bouvier M. How sacral nerve stimulation works in patients with faecal incontinence. Colorectal Disease. 2011;13(8). 
28. Shafik A, Ahmed I, El-Sibai O, Mostafa RM. Percutaneous peripheral neuromodulation in the treatment of fecal incontinence. European surgical research Europäische chirurgische Forschung Recherches chirurgicales européennes. 2003;35(2):103-7.

29. Govaert B, Pares D, Delgado-Aros S, La Torre F, Van Gemert WG, Baeten CG. A prospective multicentre study to investigate percutaneous tibial nerve stimulation for the treatment of faecal incontinence. Colorectal disease : the official journal of the Association of Coloproctology of Great Britain and Ireland. 2010;12(12):1236-41.

30. Chan CL, Scott SM, Williams NS, Lunniss PJ. Rectal hypersensitivity worsens stool frequency, urgency, and lifestyle in patients with urge fecal incontinence. Diseases of the colon and rectum. 2005;48(1):134-40.

31. Fassov J, Brock C, Lundby L, Drewes AM, Gregersen H, Buntzen S, et al. Sacral nerve stimulation changes rectal sensitivity and biomechanical properties in patients with irritable bowel syndrome. Neurogastroenterology and motility : the official journal of the European Gastrointestinal Motility Society. 2014;26(11):1597-604.

32. Rothbarth J, Bemelman WA, Meijerink WJ, Stiggelbout AM, Zwinderman AH, Buyze-Westerweel ME, et al. What is the impact of fecal incontinence on quality of life? Diseases of the colon and rectum. 2001;44(1):67-71. 
Table 1 - Obstetric risk factors and likelihood of treatment response to PTNS

\begin{tabular}{|c|c|c|c|}
\hline Obstetric risk factor & $n$ & Response rate & $\boldsymbol{P}$ \\
\hline \multicolumn{4}{|c|}{ High birthweight delivery } \\
\hline High & 10 & $40 \%$ & \multirow{2}{*}{0.87} \\
\hline Normal & 27 & $37 \%$ & \\
\hline \multicolumn{4}{|l|}{ Episiotomy } \\
\hline Yes & 23 & $39 \%$ & \multirow{2}{*}{0.84} \\
\hline No & 14 & $36 \%$ & \\
\hline \multicolumn{4}{|c|}{ Instrumentation during vaginal delivery } \\
\hline Yes & 22 & $50 \%$ & \multirow{2}{*}{0.64} \\
\hline No & 10 & $69 \%$ & \\
\hline \multicolumn{4}{|c|}{ Repair of perineal tear } \\
\hline Primary & 28 & $39 \%$ & \multirow{3}{*}{0.19} \\
\hline Secondary & 4 & $0 \%$ & \\
\hline None & 5 & $60 \%$ & \\
\hline \multicolumn{4}{|l|}{ Grade of perineal tear } \\
\hline Grade IV tear & 5 & $20 \%$ & \multirow{4}{*}{0.72} \\
\hline Grade III tear & 15 & $33 \%$ & \\
\hline Grade II tear & 15 & $47 \%$ & \\
\hline Grade I tear & 2 & $50 \%$ & \\
\hline
\end{tabular}


Table 2 - Correlation between baseline physiological parameters and treatment response

\begin{tabular}{|l|l|l|l|}
\hline & Responders & Non-responders & $P$ \\
\hline Resting pressure, & $76 \pm 18$ & $74 \pm 27$ & 0.77 \\
\hline $\begin{array}{l}\text { Squeeze pressure, } \\
\text { mm Hg }\end{array}$ & $58 \pm 31$ & $52 \pm 30$ & 0.58 \\
\hline $\begin{array}{l}\text { Cough increment } \\
\text { pressure, mm Hg }\end{array}$ & $64 \pm 29$ & $53 \pm 37$ & 0.31 \\
\hline $\begin{array}{l}\text { Threshold } \\
\text { volume, mL }\end{array}$ & $26 \pm 9$ & $35 \pm 13$ & $\underline{0.02}$ \\
\hline $\begin{array}{l}\text { Urge volume, mL } \\
\text { mm }\end{array}$ & $56 \pm 16$ & $72 \pm 26$ & $\underline{0.03}$ \\
\hline $\begin{array}{l}\text { Maximal tolerated } \\
\text { volume, mL }\end{array}$ & $111 \pm 39$ & $130 \pm 44$ & 0.17 \\
\hline Anal sensitivity, \\
mA
\end{tabular}


Table 3 - Measures of symptom severity before and after treatment in responders and non-responders

\begin{tabular}{|c|c|c|c|c|c|c|c|c|c|}
\hline & \multicolumn{3}{|c|}{ Responders } & \multicolumn{3}{|c|}{ Non-responders } & \multicolumn{3}{|c|}{ Change in values } \\
\hline & Baseline & $\begin{array}{l}\text { After } \\
\text { treatment }\end{array}$ & $\boldsymbol{P}$ & Baseline & $\begin{array}{l}\text { After } \\
\text { treatment }\end{array}$ & $P$ & Responders & $\begin{array}{l}\text { Non- } \\
\text { responders }\end{array}$ & $\boldsymbol{P}$ \\
\hline $\begin{array}{l}\text { Wexner } \\
\text { score }\end{array}$ & $13 \pm 3$ & $4 \pm 2$ & $\leq 0.01$ & $13 \pm 5$ & $12 \pm 5$ & 0.13 & -9 & -1 & $\leq 0.01$ \\
\hline \multicolumn{10}{|c|}{ Visual analogue scores } \\
\hline Bowel & $63 \pm 19 *$ & $36 \pm 24$ & $\leq 0.01$ & $48 \pm 20^{*}$ & $39 \pm 23$ & 0.10 & -26.8 & -20.0 & $\underline{0.05}$ \\
\hline Bladder & $49 \pm 30$ & $45 \pm 30$ & 0.61 & $62 \pm 30$ & $56 \pm 30$ & 0.10 & -3.6 & -11.1 & 0.71 \\
\hline \multicolumn{10}{|c|}{ Rockwood quality of life scores } \\
\hline Life & $3.2 \pm 0.6$ & $3.2 \pm 0.6$ & 0.70 & $2.8 \pm 0.8$ & $2.8 \pm 0.8$ & 0.61 & 0 & 0 & 0.50 \\
\hline $\begin{array}{l}\text { Coping \& } \\
\text { Behaviour }\end{array}$ & $2.5 \pm 0.8$ & $2.5 \pm 0.5$ & 1 & $2.1 \pm 0.7$ & $2.1 \pm 0.8$ & 0.80 & 0 & 0 & 0.86 \\
\hline
\end{tabular}




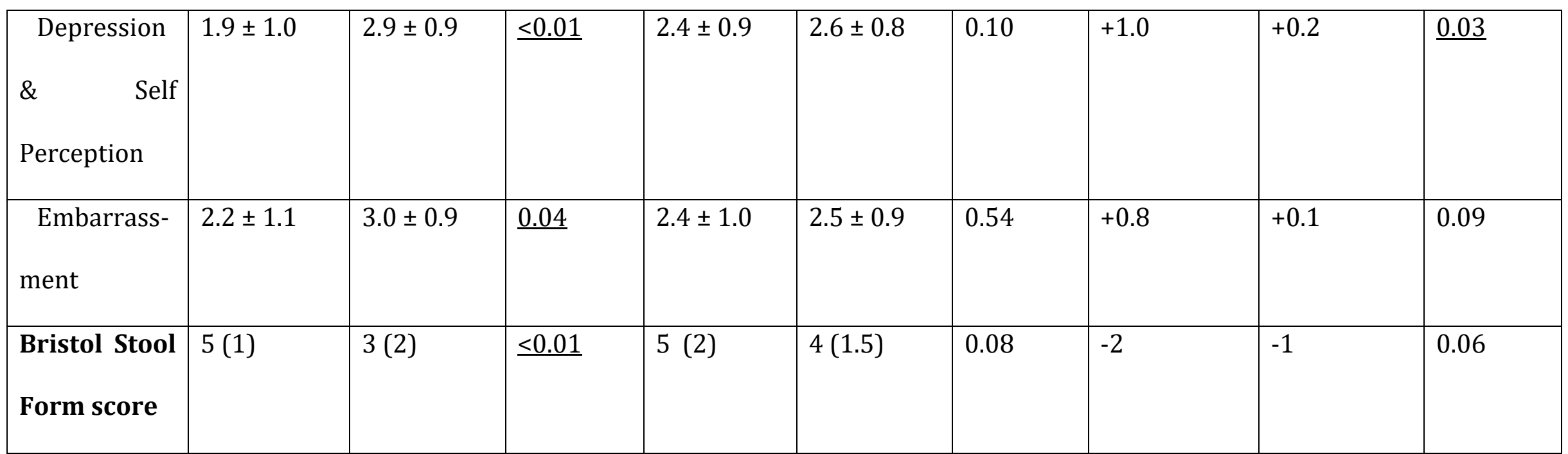

${ }^{*} P<0.01$ for responders vs. non-responders baseline values; Higher visual analogue scores correspond to greater severity of symptoms;

Lower Rockwood scores correspond to greater disability; Lower Bristol Stool Form scores correspond to firmer stool consistency; Values are means $\pm \mathrm{SD}$, medians (IQR) 